\title{
Enhanced Gastric Mucosal Damage in Rats after Chronic Treatment with Sodium Taurocholate
}

\author{
Mitsuhiro Narita and Susumu Okabe \\ Department of Applied Pharmacology, Kyoto Pharmaceutical University, Misasagi, Yamashina, Kyoto 607, Japan
}

Received October 6, 1994 Accepted January 9, 1995

\begin{abstract}
We examined whether or not 4-week treatment with $10 \mathrm{mM}$ sodium taurocholate (TC) weakens the mucosal defensive mechanism in rat stomachs. The ex vivo stomachs of anesthetized animals were perfused with $100 \mathrm{mM} \mathrm{HCl}$. In the control tap water group, mucosal application of $10 \mathrm{mM}$ TC dissolved in $100 \mathrm{mM} \mathrm{HCl}$ for $30 \mathrm{~min}$ caused a marked increase in gastric mucosal blood flow (GMBF), a reduction in transmucosal potential difference (PD), acid loss and visible mucosal damage. In the TC group, however, acidified TC applied for 30 min caused only a slight increase in GMBF, a reduction in PD, significant acid loss and severe mucosal damage. These results indicate that the mucosal defensive mechanism was extensively weakened after chronic treatment with TC.
\end{abstract}

Keywords: Sodium taurocholate, Gastric mucosal blood flow, Mucosal defense mechanism

We reported that chronic administration of $10 \mathrm{mM}$ sodium taurocholate (TC) to rats for $>\mathbf{4}$ weeks apparently desensitized capsaicin-sensitive afferent neurons (capsaicin-sensitive neurons) in the gastric mucosa, as evidenced by the reduced release of calcitonin gene-related peptide (CGRP) (1). Since chronic treatment with TC induces erosive or atrophic gastritis $(2,3)$, we proposed that the desensitization of capsaicin-sensitive neurons is one of the causal factors for such pathologic changes. It is well known that capsaicin-sensitive neurons play an important role in the maintenance of gastric mucosal integrity $(4-7)$. In fact, the degree of gastric mucosal damage induced by stress or chemical agents was apparently increased in animals preliminarily desensitized with a large amount of capsaicin compared with that induced in normal animals. Therefore, it was of interest to determine whether or not enhanced gastric damage is observed with $10 \mathrm{mM} \mathrm{TC}+100 \mathrm{mM} \mathrm{HCl}$ in animals treated with $10 \mathrm{mM}$ TC for 4 weeks.

Male Donryu rats (230-280 g; SLC, Shizuoka) were used in all experiments. The animals were allowed free access to a bottled supply of tap water containing $10 \mathrm{mM}$ TC (Difco, Detroit MI, USA; TC group) or tap water alone (as a control, tap water group), together with the usual rat chow (CE-2; Nihon Clea, Osaka) for 4 weeks. The TC solution was freshly made every 2 days. After the treatment, the rats were kept in individual cages with raised mesh bottoms to prevent coprophagy, and they were deprived of food, but allowed free access to tap water for $18 \mathrm{hr}$ before the experiments. These animals were anesthetized with urethane $(1.25 \mathrm{~g} / \mathrm{kg}$, i.p.; Tokyo Kasei, Tokyo), and then their stomachs were exposed through a midline incision and mounted in Lucite chambers according to the previously published method (8). One hour before anesthesia, all animals received omeprazole (60 mg/kg, i.p.; Hässle, Mölndal, Sweden) to inhibit basal gastric acid secretion. Under these conditions, the mucosa was perfused at a flow rate of $1 \mathrm{ml} / \mathrm{min}$ with $100 \mathrm{mM} \mathrm{HCl}\left(37^{\circ} \mathrm{C}\right)$. Gastric mucosal blood flow (GMBF) was determined by laser Doppler flowmetry (Model ALF-2100; Advance, Tokyo), the probe (1 $\mathrm{mm}$ in diameter) being softly applied to the surface of the oxyntic mucosa. The transmucosal potential difference (PD) was determined using two agar bridges, one positioned in the chamber and the other in the abdominal cavity. Changes in $\mathrm{PD}$ were continuously monitored with a recorder (Model U-228; Nippon Denshi Kagaku, Tokyo). After these parameters had become well-stabilized, the perfusion with $100 \mathrm{mM} \mathrm{HCl}$ was discontinued and the luminal solution was removed. The mucosa was then exposed to $2 \mathrm{ml}$ of either $100 \mathrm{mM} \mathrm{HCl}$ alone, $10 \mathrm{mM} \mathrm{TC}$ alone, or $10 \mathrm{mM} \mathrm{TC}$ dissolved in $100 \mathrm{mM} \mathrm{HCl}$ (acidified TC) for $30 \mathrm{~min}$. Thereafter, the mucosa was rinsed with $100 \mathrm{mM}$ $\mathrm{HCl}$, another $2 \mathrm{ml}$ of the acid instilled, and the acid perf $\mathrm{u}-$ sion resumed for the following $90 \mathrm{~min}$. When the experiments were finished, the stomachs were removed, pinned 
on a cork board, and then examined for the presence of mucosal damage under a dissecting microscope $(\times 10$; Olympus, Tokyo). The total area of the damaged mucosa was summed per stomach. In some experiments, the loss of exogenously added acid from the luminal solution, most probably due to back-diffusion of the acid into the mucosa, was determined in the chambered stomach before and after exposure of the mucosa to acidified TC for 30 min.

Data are means \pm S.E. for 6 rats per group. Statistical analysis was performed using the two-tailed Dunnett's multiple comparison test, and values of $\mathrm{P}<0.05$ being regarded as significant.

In animals that well tolerated the TC treatment for 4 weeks, the weight gain did not change compared with that in the tap water group. The rats ingested the standard chow together with TC solution $(23.9 \pm 1.9 \mathrm{ml} / \mathrm{rat} / \mathrm{day}$ : TC $183.1 \pm 14.7 \mathrm{mg} / \mathrm{rat} / \mathrm{day})$ or tap water $(23.7 \pm 1.1$ $\mathrm{ml} / \mathrm{rat} /$ day) for 4 weeks. The gastric mucosa mounted in a Lucite chamber generated a PD of about -37 to -40 $\mathrm{mV}$ and maintained a GMBF of about $5-15 \mathrm{ml} / \mathrm{min} / 100$ g. Perfusion of the gastric mucosa with $100 \mathrm{mM} \mathrm{HCl}$ did not significantly affect the basal GMBF in rats treated with either tap water or $10 \mathrm{mM}$ TC for 4 weeks. In the tap water group, mucosal application of acidified TC for 30 min produced an $85.1 \%$ increase in GMBF over the initial value. The onset of the increase was fast, and the GMBF remained elevated during the exposure to TC. Even after the removal of acidified TC from the chamber, the GMBF remained slightly higher than the basal level (Fig. 1). The basal $\mathrm{PD}$ was abruptly reduced by $33.3 \%$ and remained reduced for $90 \mathrm{~min}$, although slight recovery was observed. In contrast, the GMBF response to acidified TC in the TC group was minimal and returned to the pre-treatment level immediately after TC removal. Application of $100 \mathrm{mM} \mathrm{HCl}$ or $10 \mathrm{mM}$ TC alone did not induce any visible damage to the gastric mucosa in the tap water group. However, the stomachs treated with acidified TC showed visible damage, the damaged area being $16.7 \pm 4.5 \mathrm{~mm}^{2}$ $(\mathrm{n}=7)$ (Fig. 1). Of note was that in the TC group, acidified TC induced severe damage to the gastric mucosa. The damaged area was $39.7 \pm 5.8 \mathrm{~mm}^{2}$, which was significantly larger than that observed in the tap water group.

When the gastric mucosa of animals treated with tap water or $10 \mathrm{mM} \mathrm{TC}$ for 4 weeks was exposed to $100 \mathrm{mM}$
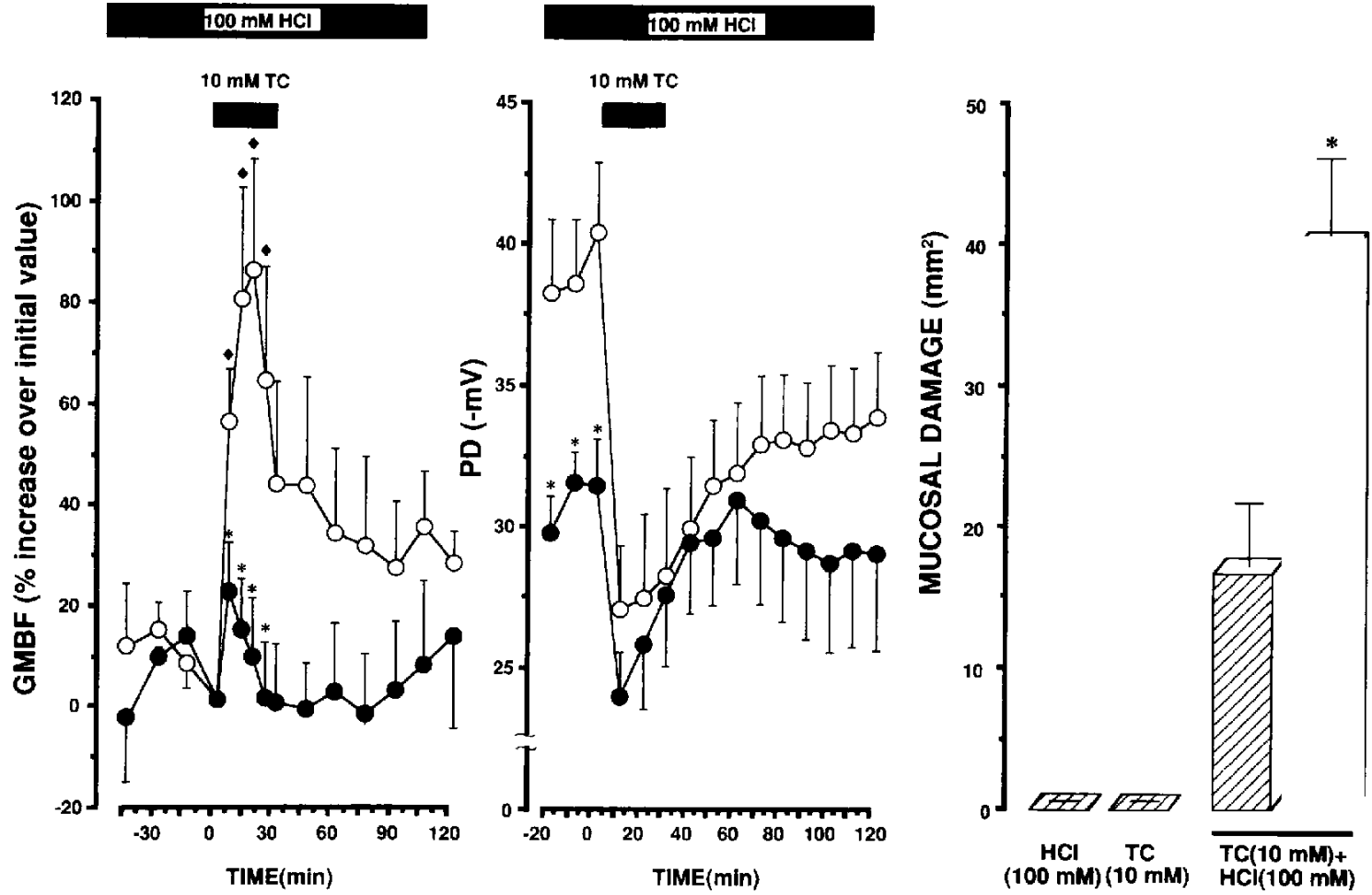

Fig. 1. Effect of $10 \mathrm{mM} \mathrm{TC} \mathrm{dissolved} \mathrm{in} 100 \mathrm{mM} \mathrm{HCl}$ on the gastric mucosal blood flow (GMBF), transmucosal potential difference (PD) and gastric mucosa determined in the ex vivo stomachs of anesthetized rats treated with $10 \mathrm{mM}$ TC or tap water for 4 weeks. TC $(10 \mathrm{mM})$ was topically applied to the stomachs for $30 \mathrm{~min}$. $O$ tap water group, $\square$ TC group. Data are means \pm 1 S.E. for 7 rats. ${ }^{*} \mathrm{P}<0.05$ or ${ }^{*} \mathrm{P}<0.05$, significantly different from the basal values or values observed in the tap water group, respectively. 
$100 \mathrm{mMHCl}$

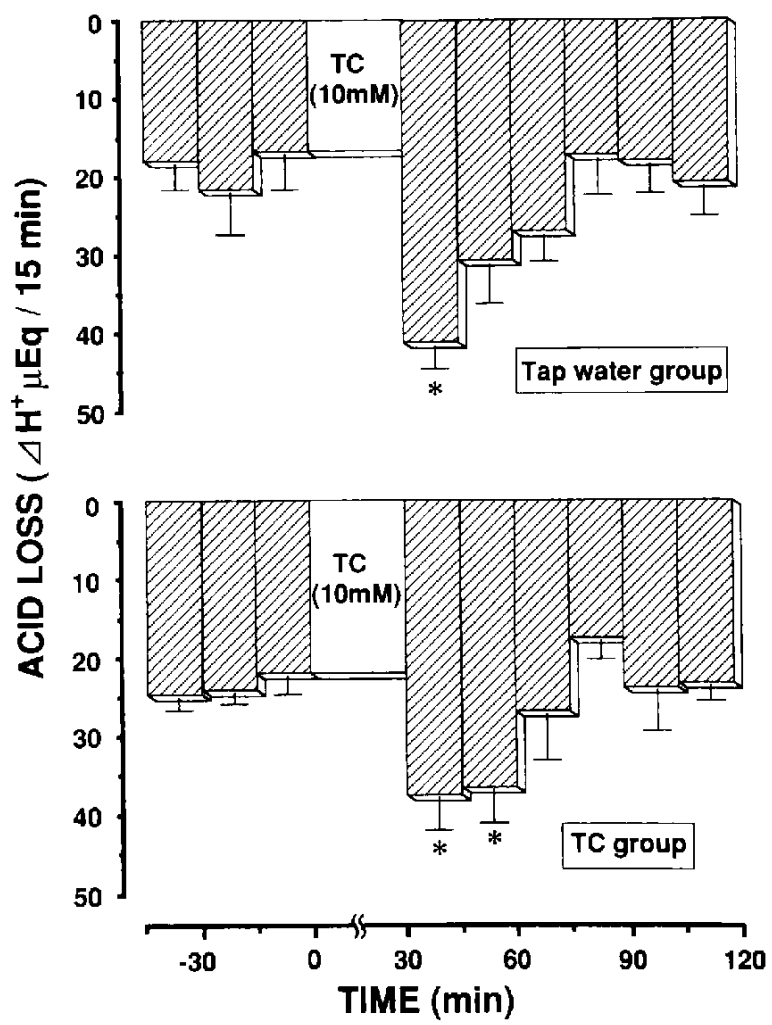

Fig. 2. Effect of $10 \mathrm{mM} \mathrm{TC}$ dissolved in $100 \mathrm{mM} \mathrm{HCl}$ on acid loss in ex vivo stomachs of anesthetized rats treated with $10 \mathrm{mM}$ TC or tap water for 4 weeks. TC $(10 \mathrm{mM})$ was topically applied to the stomachs for $30 \mathrm{~min}$. Data are means \pm 1 S.E. for 6 rats. ${ }^{*} \mathrm{P}<0.05$, significantly different from the pretreatment values.

$\mathrm{HCl}$, acid loss of about $20-25 \mu \mathrm{Eq} / 15$ min was observed (Fig. 2). In these animals, the loss of acid was significantly enhanced when acidified TC was applied (about 24.4 $\mu \mathrm{Eq} / 15 \mathrm{~min}$ in the tap water group, and $15.6 \mu \mathrm{Eq} / 15 \mathrm{~min}$ in the TC group). However, the loss decreased with time, although the decrease was not evident $45 \mathrm{~min}$ after removal of TC in the TC group.

The present study strongly indicates that $\mathrm{TC}$ treatment for 4 weeks did weaken the gastric mucosal integrity, thereby resulting in the production of severe damage in response to acidified TC. As described previously (1), TC treatment for such a long period disrupts the function of capsaicin-sensitive neurons, as evidenced by the reduced GMBF response to capsaicin. Therefore, it seems that the aggravated response resembles that observed in capsaicintreated animals (5); i.e., ethanol-induced gastric damage was worse in desensitized animals. Evangelista et al. (9) reported that $\mathrm{CGRP}_{8-37}$, a CGRP antagonist, significantly aggravated the gastric damage induced by aspirin. These results strongly suggest that a reduction of the
CGRP content in the gastric mucosa or inhibition of CGRP receptors weakens the mucosal defensive mechanism, thereby resulting in the development of gastric damage when mucosal irritants are applied. As reported by our group and others $(10,11)$, mucosal application of $10 \mathrm{mM} \mathrm{TC}$, even though we dissolved it in $100 \mathrm{mM} \mathrm{HCl}$ this time, apparently increased the GMBF in the tap water group. However, such a marked increase in GMBF was not observed in the TC group. TC is well known as one of the barrier breakers $(12,13)$. Indeed, we confirmed that there was significant acid loss from the lumen and a reduction in PD after treatment with acidified TC. It was reported that sensory neurons monitor acid back-diffusion in the superficial mucosa and trigger a protective increase in GMBF (14). It is most likely that the back-diffused acid could not increase the GMBF because of capsaicin sensitive neurons desensitized by prolonged treatment with TC. Accordingly, the mitigated GMBF was unable to carry away the back-diffused acid from the mucosa. Even in the tap water group, there was visible damage to the gastric mucosa after the mucosal application of acidified TC. However, the degree of damage was significantly lower compared with that observed in the TC-treated group. It is conceivable that acid back-diffused through the disrupted barrier might have been partly removed by the increased GMBF response to TC in the tap water group.

We conclude that prolonged treatment with TC apparently reduces the mucosal defense mechanism so as to induce gastric mucosal damage, most probably through the desensitization of capsaicin-sensitive neurons.

\section{Acknowledgments}

We wish to thank N.J. Halewood for critical reading of the manuscript.

\section{REFERENCES}

1 Narita M, Takahashi S and Okabe S: Desensitization of capsaicin-sensitive sensory neurons following prolonged treatment with sodium taurocholate in rat stomach (Abstract). Digestion 55, Supp 2, 30-31 (1994)

2 Kishimoto S: Pathophysiology of experimental gastritis and its usefulness as an experimental model. In Gastrointestinal Function-Regulation and Disturbances, Edited by Tsuchiya $M$, Nagao F, Matsuo Y and Kasuya Y, Vol 6, pp 103-116, Excerpta Medica, Tokyo (1988)

3 Narita M, Okabe S and Yamasaki K: Atrophic gastritis induced by sodium taurocholate in rats with unilateral vagotomy. Ther Res 14, 62-66 (1993)

4 Szolcsanyi J and Bartho L: Impaired defense mechanism to peptic ulcer in the capsaicin desensitized rat. In Gastrointestinal Defense Mechanism, Edited by Mozsik G, Hanninen $O$ and Javor T, pp 39-51, Pergamon Press and Akademiai Kiado, Oxford and Budapest (1981)

5 Holzer P and Sametz W: Gastric mucosal protection against 
ulcerogenic factors in the rat mediated by capsaicin-sensitive afferent neurons. Gastroenterology 91, 975-981 (1986)

6 Holzer P and Lippe ITH: Stimulation of afferent nerve endings by intragastric capsaicin protects against ethanol-induced damage of gastric mucosa. Neuroscience 27, 981-987 (1988)

7 Holzer P, Pabst MA and Lippe ITH: Intragastric capsaicin protects against aspirin-induced lesion formation and bleeding in the rat gastric mucosa. Gastroenterology 96, 1425-1433 (1989)

8 Takeuchi $\mathrm{K}$, Ishihara $\mathrm{Y}$, Okada $\mathrm{M}$, Niida $\mathrm{H}$ and Okabe S: A continuous monitoring of mucosal integrity and secretory activity in rat stomach: a preparation using a lucite chamber. Jpn J Pharmacol 49, 235-244 (1989)

9 Evangelista S, Tramontana M and Maggi CA: Pharmacological evidence for the involvement of multiple calcitonin gene-related peptide (CGRP) receptors in the antisecretory and antiulcer effect of CGRP in rat stomach. Life Sci 50, PL13-PL18 (1992)
10 Whittle BJR: Mechanisms underlying gastric mucosal damage induced by indomethacin and bile-salts, and the action of prostaglandins. Br J Pharmacol 60, 455-460 (1977)

11 Takeuchi K, Nobuhara $Y$ and Okabe S: Bile salts are endogenous mild irritants to rat gastric mucosa. In Mechanisms of Mucosal Protection in the Upper Gastrointestinal Tract, Edited by Allen A, Flemstrom G, Garner A, Silen W and Turnberg LA, pp 355-359, Raven Press, New York (1984)

12 Davenport HW: Destruction of the gastric mucosal barrier by detergents and urea. Gastroenterology 54, 175-181 (1968)

13 Ivey KJ, Den Besten L and Clifton JA: Effect of bile salts on ionic movement across the human gastric mucosa. Gastroenterology 59, 683-690(1970)

14 Holzer P, Livingston EH and Guth PH: Sensory neurons signal for an increase in rat gastric mucosal blood flow in the face of pending acid injury. Gastroenterology 101, 416-423 (1991) 